\title{
The Association Between Cervical Spine Alignment and Neck Axial Pain in Early Twenties Soldiers
}

\author{
Yoon Nae Seo', Jae Won Yu², Dong-Ju Yun ${ }^{2}$, Young Min Kwon ${ }^{3}$, Sang-Min Lee ${ }^{2 \bowtie}$ \\ 'Department of Radiology, Good Samsun Hospital, Busan, ²Department of Neurosurgery, Busan Wooridul Spine Hospital, Busan, \\ ${ }^{3}$ Department of Neurosurgery, Dong-A University Hospital, Dong-A University College of Medicine, Busan, Korea
}

\begin{abstract}
Objective: Chronic neck pain is a common clinical problem, of which the annual prevalence is high. The relationship between the cervical axial pain and its sagittal alignment is controversial. The objective of this article was to study the relationship between cervical spine alignment measured by multiple methods and cervicalgia. Methods: We surveyed the patients who visited our hospital between May 2017 and December 2017 and shortlisted those aged between 19 and 25 years and had no cervical degenerative disease in their plain film and computer tomography. We retrospectively collected demographic characteristic and clinical manifestations. We measured the sagittal cervical alignment using Cobb's angle, Jackson physiologic stress line, Harrison's tangent, disc angle in each segments, cervical sagittal vertical axis, thoracic inlet angle, neck tilt angle and T1 slope in plain cervical lateral film. Results: Of 61 patients collected, $32(52.4 \%)$ complained neck axial pain. We found that neck axial pain was significantly related to the kyphotic change of disc $(p=0.004)$, the Jackson physiologic stress line $(p=0.011)$, cervical sagittal vertical axis $(p<0.001)$, neck tilting angle $(p=$ $0.001)$ and thoracic inlet angle $(p=0.041)$. Among measured values in plain film, T1 slope and cervical sagittal vertical axis were associated with clinical manifestation presented visual analysis scale (VAS) and Neck disability index (NDI) $(p=0.035, p<0.001)$. In them, cervical vertical axis was significantly associated with clinical manifestation in multiple linear regression test $(p<0.001)$. Conclusion: We recommended that the spinal surgeons should measure a cervical vertical axis for all patients suffered from cervicalgia.
\end{abstract}

Key Words: Alignment; Cervical vertebrae; Neck pain

$\triangle$ Corresponding Author: Sang-Min Lee, Department of Neurosurgery, Busan Wooridul Spine Hospital, 1523, Jungang-daero, Dongnae-gu, Busan 47710, Korea. Tel: +82-51-559-2000, Fax: +82-51-559-2290, E-mail: hole84@naver.com

\section{INTRODUCTION}

Chronic neck pain is a common clinical problem for both the older and the younger generation ${ }^{8,20}$. The annual prevalence of cervicalgia has been reported to be from $30 \%$ to $50 \%, 8,20)$. Cervicalgia in more than $50 \%$ of people lasted for one year or more after the initial onset ${ }^{2-5,7,22,28)}$. Though the cause of neck pain is not well established yet, many lesions such as degenerative changes of the disc and facet, ligament, fascia, muscle, nerve root, and dura could be the possibilities ${ }^{30)}$.

Although some publications presented that the change in cervical sagittal alignment was considered to be the most important factor on cervicalgia, other reports showed that there was no significant correlation between the loss of normal lordotic curve and cervicalgia ${ }^{9,11-13,21,23,24,27)}$. The relationship between neck axial pain and cervical sagittal alignment is controversial.

The objective of this article was to study the relationship between cervical spine alignment measured by multiple methods and cervicalgia in young people who are in their twenties.

\section{MATERIALS AND METHODS}

\section{Patients}

We examined the patients who visited our hospital between May 2017 and December 2017 and shortlisted those aged between 19 and 25 years with cervical radiographs. The Institutional Review Board of Medical Research Institute approved this retrospective study protocol (AFMC-18-IRB-003). All patients were only soldiers not noncom officers and officers, and they had similar levels of physical labor intensity. The patients were visiting the outpatient clinic of our hospital with complaints of cervicalgia, headache, tingling sensation of hands, and subjective abnormality of sensory function in hands. We divided the patients who underwent cervical radiologic exams into two groups: the patients with cervicalgia and the ones without cervicalgia. We excluded the patients with abnormal findings on radiologic exams, such as herniation of the cervical disc at especially $\mathrm{C} 3 / 4$ or $\mathrm{C} 4 / 5$ level, ossification of the posterior lon- 
gitudinal ligament, cervical myelopathy or systemic diseases involving the cervical spine. We also excluded the patients had previous trauma or operative history of the cervical spine.

\section{Neck symptom}

We confirmed that cervicalgia was the only subjective discomfort of the cervical paraspinal muscle lesion, not including trapezius and shoulder lesions, for more than three months. Upon admission, we assessed the severity of subjective cervicalgia using the Visual Analysis Scale (VAS) and the Neck Disability Index (NDI). To evaluate VAS results, the degree of cervicalgia was quantified from 0 to 10 . We controlled the symptoms in cervicalgia group with NSAID, acetaminophen and tramadol, physical therapy and resting in hospital.

\section{Radiological analysis}

We reviewed the plain cervical lateral films and the CT scans of asymptomatic subjects and subjects with cervicalgia. All the plain films and CT scans were taken using the same method and condition by one person. The disc angle of each cervical segment was measured using Cobb method. According to Grob et al., the segmental angle was divided into three groups, straight $(0$ to +4$)$, lordotic (less than 0$)$, and kyphotic $(\text { more than }+4)^{14)}$. Sagittal alignment of the cervical spine was measured using Cobb's angle, Jackson physiologic stress line and Harrison's tangent line in plain lateral film (Fig. 1). We measured the cervical sagittal vertical axis (SVA) using the distance between a plumb line dropped from the center of the dens and the posterosuperior edge of $\mathrm{C} 7$ in plain lateral film (Fig. 2). We also measured the thoracic inlet angle (TIA), T1 slope, and neck-tilting angle (NTA), which influenced cervical sagittal balance in plain lateral film (Fig. 3).
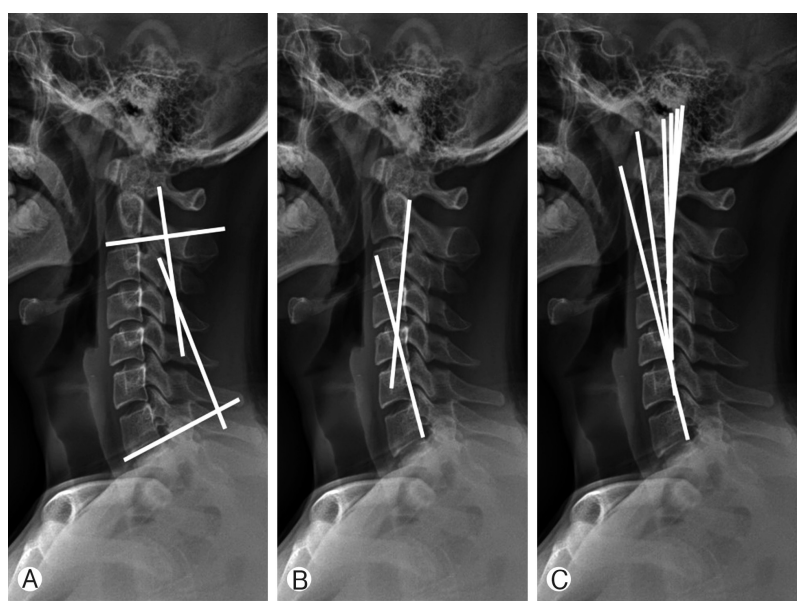

Fig. 1. Three different methods used to measure cervical lordosis. (A) Cervical Cobb's angle. (B) The Jackson physiologic stress lines. (C) Harrison's tangent method.

\section{Statistical analyses}

To ascertain the factors associated with cervicalgia, we used the chi-square test in all the patients. The Mann-Whitney U test were used to compare the average values among the patients with and without cervicalgia. Relationships between the clinical manifestations and cervical radiologic parameters in the cervicalgia group were examined using Pearson correlation coefficients. Multiple linear regression was used to analyze cervical radiologic parameters to have statistical results in Pearson correlation coefficients. All statistical analyses were performed using SPSS 12.0 version. All $p$-values $<0.05$ were considered statistically significant.
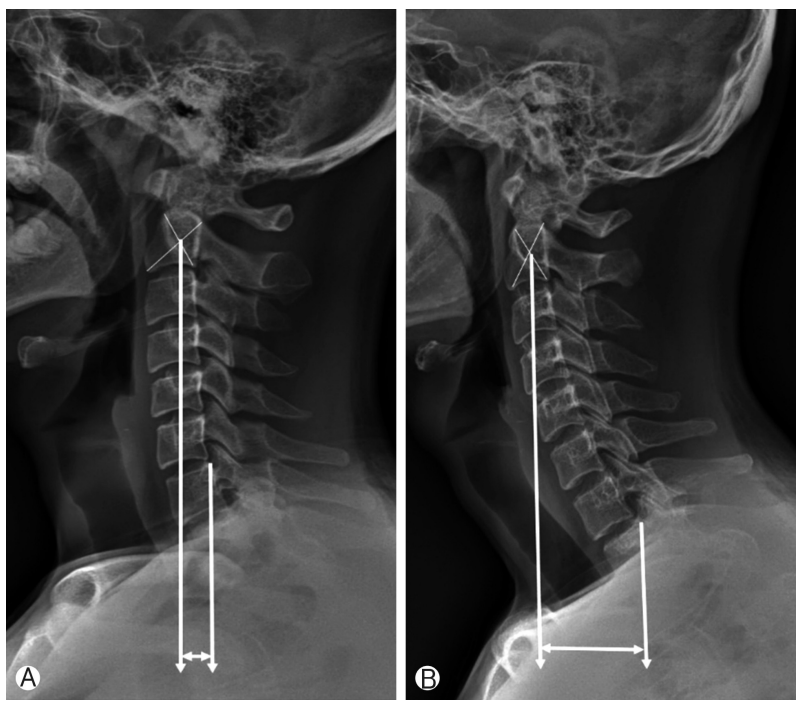

Fig. 2. Cervical sagittal vertical axis. (A) Small distance between C2 center and C7 plumb line in the group without cervicalgia. (B) Large distance between C2 and C7 plumb line in the group with cervicalgia.

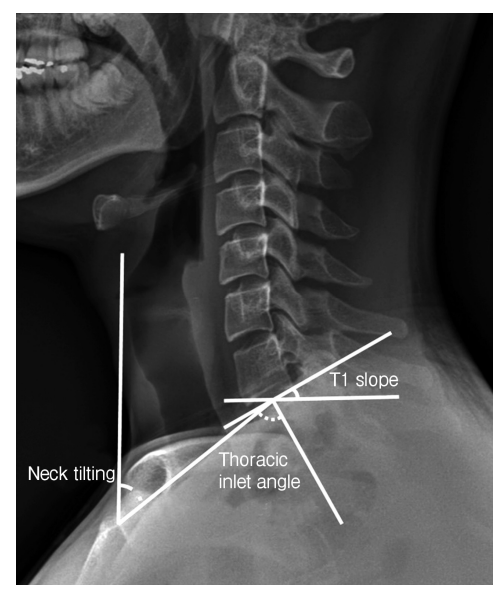

Fig. 3. Plain film demonstrating the concept of T1-slope, neck tilting angle, and thoracic inlet angle. 


\section{RESULTS}

A total of 61 patients who visited our hospital were enrolled in our study. From these patients, 32 had cervicalgia, and they constituted the pain group (cervicalgia) and 29 of them had no cervicalgia (no cervicalgia). Only male patients were included in our study, and the median age of each group showed similar results (cervicalgia group: median age was 21 years; interquartile range [IQR], 20-21 years vs. no cervicalgia: median age was 21 years; interquartile range [IQR], 20-22 years).

\section{Disc angle}

There were no significant differences of the segmental curvature at any levels between the cervicalgia and no cervicalgia groups. The segmental kyphotic deformity was revealed in more than one segment in 14 patients (43.8\%) from the cervicalgia group as compared to three patients $(10.3 \%)$ from the no cervicalgia group ( $p=0.004)$. The most common level of kyphotic deformity was at $\mathrm{C} 4 / 5(\mathrm{n}=8,44.44 \%)$, followed by $\mathrm{C} 3 / 4 \mathrm{n}=5$, $27.78 \%), C 5 / 6(n=4,22.22 \%)$, and $C 2 / 3(n=1,5.56 \%)$ in the cervicalgia group. The angle of kyphotic deformity showed no significant difference in each group $(p=0.275)$ (Table 1$)$.

\section{The lordosis of cervical spine}

The Cobb's angle measured from $\mathrm{C} 2$ to $\mathrm{C} 7$ was not significantly different in each group: the median angle of 8 degrees
(3.25-11.5) in the cervicalgia group vs. the median angle of 7 degrees (3-16.5) in the no cervicalgia group $(p=0.821)$. The Jackson physiologic stress line showed statistically significant results in these two groups $(6.5 \pm 12.25$ with cervicalgia vs. $14.03 \pm 9.9$ without cervicalgia; $p=0.011$ ). The Harrison's posterior tangent method did not reveal a statistically significant difference between each group $(18.78 \pm 9.24$ with cervicalgia vs. $22.55 \pm 9.85$ without cervicalgia; $p=0.128$ ) (Table 1 ).

\section{Cervical sagittal vertical axis}

The mean cervical sagittal vertical axis for the cervicalgia group was $25.59 \pm 6.47$. For the no cervicalgia group, the corresponding value was $15.17 \pm 7.02$. There was a significant difference in the cervical sagittal vertical axis in these groups ( $p$ $<0.001)$.

\section{Factors influencing cervical sagittal balance}

The T1 slope did not show a statistically significant difference between each group $(21.75 \pm 5.87$ with cervicalgia vs. $23.09 \pm$ 6.06 without cervicalgia; $p=0.387$ ). In the cervicalgia group, neck tilting angle and thoracic inlet angle revealed significant differences. The median NT angle was 47 degrees ([IQR] 43.553.5 degrees) and the median TIA was 72 degrees ([IQR] 65-75.5 degrees) in the cervicalgia group, while the median NT angle was 43.5 ([IQR] 40.0-47.0 degrees) and the median TIA was 66.5 degrees ([IQR] 60-73.0 degrees) in the no cervicalgia group ( $p=0.001$ for NT, $p=0.041$ for TIA) (Table 1).

Table 1. The radiologic findings in each groups

\begin{tabular}{|c|c|c|c|}
\hline & Cervicalgia & No cervicalgia & $p$-valure \\
\hline \multicolumn{4}{|l|}{ Discal angle } \\
\hline $\mathrm{C} 2 / 3$ & $2.0(1.0-4.5)$ & $4.5(1.3-6.0)$ & 0.079 \\
\hline $\mathrm{C} 3 / 4$ & $3.0(1.0-5.0)$ & $2.5(1.0-6.5)$ & 0.810 \\
\hline $\mathrm{C} 4 / 5$ & $2.0(0.5-3.5)$ & $1.0(-4.5-3.0)$ & 0.101 \\
\hline $\mathrm{C} 5 / 6$ & $2.0(1.0-4.0)$ & $2.0(0.3-3.0)$ & 0.131 \\
\hline $\mathrm{C} 6 / 7$ & $6.0(3.0-9.5)$ & $5.0(3.3-9.0)$ & 0.867 \\
\hline Kyphotic deformity & $14(43.8)$ & $3(10.3)$ & 0.004 \\
\hline $\mathrm{C} 2 / 3$ & $1(5.6)$ & $0(0.0)$ & \\
\hline $\mathrm{C} 3 / 4$ & $5(27.8)$ & $0(0.0)$ & \\
\hline $\mathrm{C} 4 / 5$ & $8(44.4)$ & $3(100.0)$ & \\
\hline $\mathrm{C} 5 / 6$ & $4(22.2)$ & $0(0.0)$ & \\
\hline Cobb's angle & $8(3.25-11.50)$ & $7(3.00-16.50)$ & 0.821 \\
\hline Jackson stress line & $6.50 \pm 12.25$ & $14.03 \pm 9.90$ & 0.011 \\
\hline Harrison's tangent method & $18.78 \pm 9.24$ & $22.55 \pm 9.85$ & 0.128 \\
\hline T1 slope & $21.75 \pm 5.87$ & $23.09 \pm 6.06$ & 0.387 \\
\hline Neck tilting angle & $47.00[43.50-53.50]$ & $43.50[40.00-47.00]$ & 0.001 \\
\hline Thoracic inlet angle & $72.00[65.00-75.50]$ & $66.50[60.00-73.00]$ & 0.041 \\
\hline Cervical vertical axis & $25.59 \pm 6.47$ & $15.17 \pm 7.02$ & $<0.001$ \\
\hline
\end{tabular}




\section{Relationship between measured values in plain film and severity of cervicalgia}

There was a significant correlation between cervical sagittal vertical axis and the VAS for cervicalgia $(\mathrm{r}=0.757, p<0.001)$. T1 slope angle also showed a significant relationship with the VAS for cervicalgia $(\mathrm{r}=0.288, p=0.035)$. Cervical sagittal vertical axis and $\mathrm{T} 1$ slope angle also showed a significant relation with the NDI score $(\mathrm{r}=0.836, p<0.01$ and $\mathrm{r}=0.392, p=0.027)$ (Table 2). Multiple linear regression revealed that the cervical sagittal vertical axis had a significant correlation with NDI and VAS in the cervicalgia group (Table 3).

\section{DISCUSSION}

In this study, we investigated the relationship between cervical alignment and cervical axial pain. Our findings revealed that the cervical vertical axis was the most relevant factor for cervicalgia. The Jackson stress line, neck tilting angle and thoracic inlet angle were also associated with cervical axial pain.

The normal lordotic curvature of the cervical spine allows efficient absorption of the load applied to the spine and enables fluid motion and optimal functions ${ }^{16,32,33)}$. The posterior muscles, ligaments, and bony parts play crucial roles preserving this lordotic cervical curvature. Biomechanical articles show that the posterior parts of the cervical spine support $65 \%$ of the normal compressive forces but the anterior parts support $35 \%$ of them ${ }^{29)}$. Degenerative changes in the cervical spine were accompanied with shortening of the anterior and posterior vertebral column and facet arthropathies, which results in an alte- ration of the sagittal balance of the spine ${ }^{11,15,34)}$. When disruption of the posterior cervical parts occur, the anterior supports cannot withstand the increased axial loading, which causes the loss of normal lordotic cervical curve. At the biomechanical point of view, this loss of normal function of the cervical lordotic curvature could be a cause of cervicalgia due to muscular imbalance and overload of the partial parts of cervical spine ${ }^{18,19,25)}$. As a result, the lordotic curvature is ideal for the cervical spine. There are many methods in measuring the cervical curvature, but identifying which method is best in measuring clinical manifestations such as cervicalgia was controversial.

Grob et al. showed that the segmental kyphotic changes in the cervical spine was not associated with clinical manifestations such as cervical axial pain and shoulder pain ${ }^{14}$. Our study revealed that the incidence of segmental kyphotic change in the cervicalgia group was higher than the no cervicalgia group. Compared to our study, Grob et al. included older age; hence, there was a higher incidence of segmental kyphotic changes in the cervical spine in their study ${ }^{14)}$. This factor could have affected the results of their study. The kyphotic changes of the cervical disc spaces were degenerative, which caused axial overload in the anterior cervical column ${ }^{1,6)}$. The other study revealed that this pathologic change in the cervical spinal disc was an important pathogenic factor of cervicalgia ${ }^{30)}$. We hypothesized that the kyphotic change in each segment was affected by cervical axial pain.

We found that the Jackson physiologic stress line was associated with neck axial pain, while other methods measuring cervical lordosis were not. The relationship between sagittal alignment and neck symptoms was controversial. Harrison et

Table 2. The relationship between clinical manifestation (VAS, NDI) and radiologic findings

\begin{tabular}{|c|c|c|c|c|}
\hline & \multicolumn{2}{|c|}{$\mathrm{VAS}^{*}$} & \multicolumn{2}{|c|}{$\mathrm{NDI}^{\dagger}$} \\
\hline & $\mathrm{P}$ & $\mathrm{R}$ & $\mathrm{P}$ & $\mathrm{R}$ \\
\hline Discal kyphotic change & 0.187 & 0.375 & 0.128 & 0.427 \\
\hline Cobb's angle & 0.183 & -0.241 & 0.266 & -0.203 \\
\hline Jackson's stress line & 0.274 & -0.200 & 0.398 & -0.155 \\
\hline Harrison's tangent method & 0.844 & 0.036 & 0.637 & 0.87 \\
\hline Sagittal vertical axis & $<0.001$ & 0.858 & $<0.001$ & 0.836 \\
\hline T1 slope & 0.034 & 0.376 & 0.027 & 0.397 \\
\hline Neck tilting angle & 0.979 & 0.005 & 0.057 & 0.756 \\
\hline Thoracic inlet angle & 0.488 & -0.127 & 0.344 & -0.173 \\
\hline
\end{tabular}

VAS: Visual analogue scale, ${ }^{\dagger}$ NDI: Neck Disability Index.

Table 3. Multiple linear regression between clinical manifestation and radiologic findings having relationship

\begin{tabular}{|c|c|c|c|c|c|c|}
\hline & \multicolumn{3}{|c|}{$\operatorname{VAS}^{*}\left(\mathrm{R}^{2}=0.753\right)$} & \multicolumn{3}{|c|}{$\mathrm{NDI}^{\dagger}\left(\mathrm{R}^{2}=0.707\right)$} \\
\hline & $\beta$ & S.E & $p$-value & $\beta$ & S.E & $p$-value \\
\hline $\mathrm{SVA}^{\dagger}$ & 0.944 & $0.220 \pm 0.026$ & $<0.001$ & 0.899 & $0.729 \pm 0.099$ & $<0.001$ \\
\hline T1 slope & -0.154 & $-0.038 \pm 0.028$ & 0.179 & -0.112 & $-0.097 \pm 0.105$ & 0.363 \\
\hline
\end{tabular}

VAS: Visual analogue scale, ${ }^{\dagger}$ NDI: Neck Disability Index, ${ }^{\dagger}$ SVA: Sagittal vertical axis. 
al. used the circular modeling method to measure the sagittal alignment $^{17}$. It showed that the pain groups were more associated with hypolordotic curvatures or large radii of curvature than the normal groups ${ }^{17}$. The retrospective study showed that the degree of cervical lordosis measured with Harrison's tangent line had moderate diagnostic accuracy on chronic neck pain (sensitivity 0.46 , specificity 0.97 ) or on acute neck pain (sensitivity 0.67 , specificity 0.61$)^{17)}$. On the other hand, Grob et al. reported that the association between cervical spine alignment and neck pain in more than 100 people older than 45 years old had no relationship with any of the clinical manifestations (duration, frequency, intensity, radiating pain, neurologic dysfunction, and disability) and the global cervical curvature ${ }^{14)}$. The other study on the association between radiologic findings of the cervical spine and neck symptoms in a Japanese community population showed that there is no association between cervical sagittal alignment and neck symptoms ${ }^{10)}$.

In our study, the patients suffering from cervical axial pain had higher TIA and NTA than the patients without cervicalgia. On the contrary, Knott et al. showed that a higher T1 slope was associated with cervical axial pain ${ }^{26}$. This study showed opposite results. Our report and the study by Knott et al. included small sample sizes; our study just enrolled 61 patients and Knott et al. included 52 patients with cervical pain and deformity. Therefore, we believe that a prospective study including a large population without degenerative changes was needed to investigate the effect of cervical parameters, such as NTA, T1 slope, and TIA to measure cervical axial pain.

The study by Tang et al. was the only report on the association of cervical sagittal alignment with clinical outcome ${ }^{31)}$. This article included patients that underwent operations. Our study was the only one on cervical sagittal vertical alignment in patients with cervicalgia that did not undergo operations. Tang et al. showed that C2-C7 SVA was negatively correlated with SF-36 physical component score and was positively associated with NDI score, but VAS was not associated with cervical sagittal alignment ${ }^{31)}$. As a result, they suggested that positive cervical alignment measured by C2-C7 SVA negatively affected quality of life. Our study revealed that the NDI and VAS score was also positively related with cervical vertical alignment. This correlation may be explained by the "Conus of Economy" theory; it means that the body preserves the balance by regulating the center of gravity over a perimeter that is as narrow as possible $^{31)}$. When applying this theory to cervical alignment, it is suggested that to increase sagittal vertical axis, the muscles in the posterior part of the cervical spine must be more contracted to preserve balance. We suggested that the chronic contraction of the posterior cervical muscles showed poor clinical manifestations.

Our article has some limitations. The first limitation is that our study is a retrospective study. The seconds, we only reviewed subject's simple plain X-ray and CT scan, didn't check MRI image so we didn't analysis the degree of degeneration at each cervical level in all subjects. Third, all subjects were just soldiers doing compulsory services, so they may present the cervicalgia to obtain second benefits such as hospitalization, resting and exclusion from their jobs.

\section{CONCLUSION}

Our study showed that the cervical vertical axis was the most valuable method in correlating with clinical manifestations such as NDI score and VAS in early twenties soldiers. The cervical vertical axis was directly correlated with NDI and VAS; hence, we recommended that the spinal surgeons should measure cervical vertical axis for early twenties patients who suffer from cervicalgia without abnormality in radiologic exams.

\section{- Conflicts of interest}

This article was retrospective study, so we didn't obtain informed consent. There was no conflict of interest in this article. We receive the approval of the institutional review board.

\section{REFERENCES}

1. Albert TJ, Vacarro A: Postlaminectomy kyphosis. Spine (Phila Pa 1976) 23(24):2738-2745, 1998

2. Borghouts JA, Koes BW, Bouter LM: The clinical course and prognostic factors of non-specific neck pain: a systematic review. Pain 77:1-13, 1998

3. Carroll LJ, Hogg-Johnson S, van der Velde G, Haldeman S, Holm LW, Carragee EJ, et al.: Course and prognostic factors for neck pain in the general population: results of the Bone and Joint Decade 2000-2010 Task Force on Neck Pain and Its Associated Disorders. Spine (Phila Pa 1976) 33:75-82, 2008

4. Côté P, Cassidy JD, Carroll LJ, Kristman V: The annual incidence and course of neck pain in the general population: a populationbased cohort study. Pain 112:267-273, 2004

5. Croft PR, Lewis M, Papageorgiou AC, Thomas E, Jayson MI, Macfarlane GJ, et al.: Risk factors for neck pain: a longitudinal study in the general population. Pain 93:317-325, 2001

6. Deutsch H, Haid RW, Rodts GE, Mummaneni PV: Postlaminectomy cervical deformity. Neurosurg Focus 15(3): E5, 2003

7. Enthoven P, Skargren E, Oberg B: Clinical course in patients seeking primary care for back or neck pain: a prospective 5-year follow-up of outcome and health care consumption with subgroup analysis. Spine (Phila Pa 1976) 29:2458-2465, 2004

8. Fejer R, Kyvik KO, Hartvigsen J: The prevalence of neck pain in the world population: a systematic critical review of the literature. Eur Spine J 15:834-848, 2006

9. Friedenberg ZB, Miller WT: Degenerative disc disease of the cervical spine. J Bone Jt Surg Am 45:1171-1178, 1963

10. Gentaro Kumagai, Atsushi Ono, Takuya Numasawa, Kanichiro Wada, Ryo Inoue, Hiroki Iwasaki, et al.: Association between roentgenographic findings of the cervical spine and neck symptoms in a Japanese community population. J Orthop Sci 19:390397, 2014

11. Gore DR, Sepic SB, Gardner GM: Roentgenographic findings 
of the cervical spine in asymptomatic people. Spine (Phila Pa 1976) 11:521-524, 1986

12. Gore DR, Sepic SB, Gardner GM, Murray MP: Neck pain: a long-term follow-up of 205 patients. Spine (Phila Pa 1976) 12: $1-5,1987$

13. Greenfield B, Catlin PA, Coats PW, Green E, McDonald JJ, North C: Posture in patients with shoulder overuse injuries and healthy individuals. J Orthop Sports Phys Ther 21:287-295, 1995

14. Grob D, Frauenfelder H, Mannion A. F: The association between cervical spine curvature and neck pain. Eur Spine J 16:669-678, 2007

15. Hardacker JW, Shuford RF, Capicotto PN, Pryor PW: Radiographic standing cervical segmental alignment in adult volunteers without neck symptoms. Spine (Phila Pa 1976) 22(13):14721480, 1997

16. Harrison DD, Troyanovich SJ, Harrison DE, Janik TJ, Murphy DJ: A normal sagittal spinal configuration: a desirable clinical outcome. J Manipulative Physiol Ther 19:398-405, 1996

17. Harrison DD, Harrison DE, Janik TJ, Cailliet R, Ferrantelli JR, Haas JW, et al.: Modeling of the sagittal cervical spine as a method to discriminate hypolordosis: results of elliptical and circular modeling in 72 asymptomatic subjects, 52 acute neck pain subjects, and 70 chronic neck pain subjects. Spine (Phila Pa 1976) 29:24852492, 2004

18. Harrison DE, Harrison DD, Janik TJ, William Jones E, Cailliet R, Normand M: Comparison of axial and flexural stresses in lordosis and three buckled configurations of the cervical spine. Clin Biomech (Bristol, Avon) 16(4):276-284, 2001

19. Harrison DE, Jones EW, Janik TJ, Harrison DD: Evaluation of axial and flexural stresses in the vertebral body cortex and trabecular bone in lordosis and two sagittal cervical translation configurations with an elliptical shell model. J Manipulative Physiol Ther 25(6):391-401, 2002

20. Hartvigsen J, Frederiksen H, Christensen K: Back and neck pain in seniors-prevalence and impact. Eur Spine J 15:802-806, 2006

21. Haughie LJ, Fiebert IM, Roach KE: Relationship of forward head posture and cervical backward bending to neck pain. J Man Manip Ther 3:91-97, 1995

22. Hoving JL, de Vet HC, Twisk JW, Devillé WL, van der Windt
D, Koes BW, et al.: Prognostic factors for neck pain in general practice. Pain 110:639-645, 2004

23. Kebaetse M, McClure E, Pratt NE: Thoracic position effect on shoulder range of motion, strength, and three-dimensional scapular kinematics. Arch Phys Med Rehabil 80:945-950, 1999

24. Kibler WB, McMullen J: Scapular dyskinesis and its relation to shoulder pain. J Am Acad Orthop Surg 11:142-151, 2003

25. Kleinn F: Zur Rolle strukturell fixierter Kyphosen und Skoliosen bei chronischen Rückenbeschwerden. Orthop Praxis 34:456-459, 1998

26. Knott PT, Mardjetko SM, Techy F: The use of the T1 sagittal angle in predicting overall sagittal balance of the spine. Spine (Phila Pa 1976) 10:994-998, 2010

27. Lewis JS, Green A, Wright C: Subacromial impingement syndrome: The role of posture and muscle imbalance. J Shoulder Elbow Surg 14:385-392, 2005

28. Martin BI, Deyo RA, Mirza SK, Turner JA, Comstock BA, Hollingworth W, et al. : Expenditures and health status among adults with back and neck problems. JAMA 299:656-664, 2008

29. Pal GP, Sherk HH: The vertical stability of the cervical spine. Spine (Phila Pa 1976) 13(5):447-449, 1998

30. Seong HY, Lee MK, Jeon SR, Roh SW, Rhim SC, Park JH: Prognostic factor analysis for management of chronic neck pain: Can we predict the severity of neck pain with lateral cervical curvature? J Korean Neurosurg Soc 60(4):456-464, 2017

31. Tang JA, Scheer JK, Smith JS, Deviren V, Bess S, Hart RA, et al.: The impact of standing regional cervical sagittal alignment on outcomes in posterior cervical fusion surgery. Neurosurgery 71(3):662-669, 2012

32. Vialle R, Levassor N, Rillardon L, Templier A, Skalli W, Guigui $\mathrm{P}$ : Radiographic analysis of the sagittal alignment and balance of the spine in asymptomatic subjects. J Bone Joint Surg 87:260267, 2005

33. Villavicencio AT, Babuska JM, Ashton A, Busch E, Roeca C, Nelson EL, et al.: Prospective, randomized, double-blind clinical study evaluating the correlation of clinical outcomes and cervical sagittal alignment. Neurosurgery 68:1309-1316, 2011

34. Weh L, Rottker H: Functional analysis of the cervical spine in healthy persons. Radiologe 30(2):87-91, 1990 